\title{
Comparing Live $Z$-Score Training and Theta/Beta Protocol to Reduce Theta-to-Beta Ratio: A Pilot Study
}

\author{
Rubén Pérez-Elvira ${ }^{*}$, Javier Oltra-Cucarella ${ }^{2}$, and José A. Carrobles ${ }^{3}$ \\ ${ }^{1}$ Laboratorio de Neuropsicofisiología, NEPSA Rehabilitación Neurológica, Salamanca, Spain \\ 2Departamento de Psicología de la Salud, Área de Psicología Evolutiva y de la Educación, Universidad Miguel \\ Hernández, Elche, Spain \\ ${ }^{3}$ Departamendo de Personalidad, Evaluación y Tratamientos Psicológicos, Universidad Autónoma de Madrid, Madrid, \\ Spain
}

\begin{abstract}
Objective/Background: Theta-to-Beta ratio is one of the most studied electroencephalography findings in ADHD in the neurotherapy field, alongside the neurofeedback (NF) protocols whose objective is reducing it. The NF field has developed to a great level in the last decade. One of the approaches that became of particular interest to the clinicians has been Z-score training (ZT). In general, there are still a few studies about the efficacy of ZT and even fewer that compare this technique with the classic protocols. This study aimed to check the efficacy of ZT in reducing Theta-to-Beta ratio. Participants: 15 patients diagnosed with combined type ADHD aged 7 to 18, recruited in retrospect. Methods: The participants were divided in two groups. One of the groups was provided with the ZT intervention and the other one, the Theta/Beta $(T / B)$ protocol. Both groups went through ten 30-min NF sessions using videos selected by themselves as a reinforcement. The main outcomes of this study were the patients' Theta-to-Beta ratio metrics. Results: Both groups showed a decrease in Theta-to-Beta ratio; the ZT group showed a decrease of 1.02 points average and the T/B group showed a decrease of 0.15 points average, only being statistically significant for the ZT group.
\end{abstract}

Keywords: neurofeedback; Z-score training; Theta-to-Beta ratio

Citation: (Arial 8pt) Pérez-Elvira, R., Oltra-Cucarella, J., \& Carrobles, J. A. (2020). Comparing live Z-score training and Theta/Beta protocol to reduce Theta-to-Beta ratio: A pilot study. NeuroRegulation, 7(2), 58-63. https://doi.org/10.15540/nr.7.2.58

*Address correspondence to: Prof. Javier Oltra-Cucarella, PhD, Departamento de Psicología de la Salud, Área de Psicología Evolutiva y de la Educación, Edificio Altamira, Campus de Elche, Despacho E15 - P.1 - 035, 03207, Elche, Spain. Email: joltra@umh.es

Copyright: @ 2020. Pérez-Elvira et al. This is an Open Access article distributed under the terms of the Creative Commons Attribution License (CC-BY).

\section{Edited by:}

Rex L. Cannon, PhD, SPESA Research Institute, Knoxville, Tennessee, USA

Reviewed by:

Rex L. Cannon, PhD, SPESA Research Institute, Knoxville, Tennessee, USA

Estate M. Sokhadze, PhD, University of South Carolina, School of Medicine Greenville, Greenville, South Carolina, USA

\section{Introduction}

Biofeedback (BF) is an applied field within psychophysiology. Neurofeedback (NF), which is a subdivision of $\mathrm{BF}$, is focused on controlling the electroencephalographic (EEG) activity (Carrobles, 2016). NF is based on the operant conditioning (i.e., behavior modification by rewards and punishments) application to the EEG activity (Monastra, Monastra, \& George, 2002). The EEG activity is recorded by a device (amplifier) and processed with specialized software that allows it to break down the EEG into frequency bands (Delta, Theta, Alpha, Beta, etc.), and also to measure the average voltage or the amplitude of each band at a certain point (Carrobles, 2016; Demos, 2005).

In classical NF, also known as power training, it is possible to reinforce, inhibit, or ignore the different bands. For the bands that are being reinforced, an amplitude threshold is established that must be exceeded to obtain feedback. For the bands that are being inhibited, a threshold is established, and the amplitudes must remain under it in order to obtain reinforcement. When there is more than one frequency band being reinforced and/or inhibited, all set thresholds must be within the set range to receive feedback (Demos, 2005). This feedback—which can be visual (e.g., films), auditory (e.g., music), vibratory, 
or mixed-is contingent on the fulfillment of the thresholds for each band present in the EEG.

Throughout the years, there have been a number of protocols within the context of the NF power training which are nowadays considered by the literature as classical protocols. Ever since the Monastra et al. (1999; Monastra, Lubar, \& Linden, 2001) studies showed that the finding of a Theta-to-Beta ratio could be a possible indicator of attention-deficit/ hyperactivity disorder (ADHD), there began to emerge a great number of studies that used the Theta/Beta (T/B) protocol as a possible intervention in ADHD cases (Arns, de Ridder, Strehl, Breteler, \& Coenen, 2009; Bakhshayesh, Hänsch, Wyschkon, Rezai, \& Esser, 2011; Leins et al., 2007). Among those classical protocols, we find the T/B applied in general to $\mathrm{Cz}$ (one of the International 10/20 system locations) that inhibits Theta-to-Beta ratio, which essentially means inhibiting the Theta activity and enhancing the Beta activity at the sensorimotor cortex (Monastra et al., 2005; Rossiter, 2002). When the patient meets the criteria, he subsequently receives the reinforcement (Monastra et al., 2005; Rossiter \& La Vaque, 1995).

Even though this protocol was first used to treat the ADHD, it has also been applied as a one-size-fits-all protocol for other conditions such as insomnia (Hammer, Colbert, Brown, \& Ilioi, 2011; Schabus et al., 2014), cognitive performance (Doppelmayr \& Weber, 2011), impulsivity (Bluschke, Broschwitz, Khol, Roessner, \& Beste, 2016; Liu, Hou, Sourina, \& Bazanova, 2016), and executive functions or autism (Kouijzer, de Moor, Gerrits, Congedo, \& van Schie, 2009).

In recent years, technological advances have allowed new possibilities to be created in the field of NF (Hammer et al., 2011) through different paradigms: amplitude neurofeedback, Z-score-based neurofeedback, infralow frequency neurofeedback, infraslow fluctuation neurofeedback, or low resolution electromagnetic tomography analysis (LORETA)based neurofeedback.

Since its inception at the beginning of the 2000s (Collura, 2008, 2014), Z-score training (ZT) has attracted interest among the NF scientific community resulting in several case (Collura, Guan, Tarrant, Bailey, \& Starr, 2010; Koberda, Moses, Koberda, \& Koberda, 2012; Pérez-Elvira, Carrobles, López Bote, \& Oltra-Cucarella, 2019; Pérez-Elvira et al., 2018; Smith, 2008) and group studies (Groeneveld et al., 2019; Hammer et al., 2011; Krigbaum \& Wigton, 2015; Wigton, 2014; Wigton \& Krigbaum, 2015). In
ZT all the patients' EEG Z-scores from all elements (absolute power, relative power, coherence, etc.) are computed and collected at all times, the percentage of $Z$-scores within a specific range (for instance, \pm 1 $S D$ ) is calculated, and the patient receives feedback every time the percentage of Z-scores within the normal range is equal to or higher than a requested percentage.

ZT has shown efficacy in different pathologies such as ADHD, epilepsy, migraine, depression, anxiety, insomnia, and learning disorders (Guan, 2016; Hammer et al., 2011; Pérez-Elvira et al., 2019; Walker, 2016). In fact, there are some authors, such as Lubar (2015), who indicate that NF based on Zscore promotes faster learning than classical NF. This has also been partly verified by the Wigton and Krigbaum studies (Krigbaum \& Wigton, 2015; Wigton \& Krigbaum, 2015) that presented a normalization of the EEG in approximately 10 sessions, against the average 40 necessary in the classical NF, (Krigbaum \& Wigton, 2014; Thatcher, 2013; Wigton, 2013; Wigton \& Krigbaum, 2015) or even more than 60 in some cases (Sürmeli \& Ertem, 2011; Sürmeli, Erthem, Eralp, \& Kos, 2012).

The aim of this investigation was to study ZT's capacity to reduce Theta-to-Beta ratio while comparing that intervention with an active control group who followed a T/B protocol.

\section{Methods}

\section{Subjects}

A total of 15 subjects, 12 boys and 3 girls from NEPSA Rehabilitación Neurológica (a Neurorehabilitation Clinic) who went looking for NF treatment, took part in this study, which has a gender ratio of $4: 1$ to represent the ratio of boys to girls usually found in ADHD. Their data were retrospectively analyzed. The inclusion criteria were:

1) being diagnosed with combined type ADHD by a school psychologist, a neurologist, and/or neuropediatrician,

2) being between the ages of 7 and $18(M=12$, $S D=3.5$, range $=7-18$ )

3) having a Theta-to-Beta ratio higher that what is to be expected for that age range (Demos, 2019),

4) not taking any medication, and

5) having completed $10 \mathrm{NF}$ sessions between September and December 2018.

Moreover, all of the subjects took an intelligence test (Wechsler Intelligence Scale for Children - Fourth 
Edition [WISC-IV] or Wechsler Abbreviated Scale of Intelligence - Second Edition [WASI-II]) and scored within the normal range.

The subjects or the subjects' parents signed an informed consent to apply the treatment on them and for the subsequent anonymized use of their data for researching purposes. The intervention took place at NEPSA Rehabilitación Neurológica, a neurological rehabilitation clinic authorized by the Health Department of the Autonomous Community of Castile-Leon (Spain). The Health Department granted approval for psychophysiological interventions of this kind within the context of psychological treatments.

\section{Instruments and Procedure}

\section{Quantitative EEG Recording and Analysis}

A quantitative EEG ( $q E E G$ ) was recorded before starting the NF intervention and after $10 \mathrm{NF}$ sessions. To record the EEG, the subjects were fitted with a 19channel Free-cap (Institute for EEG-Neurofeedack [IFEN], Baldham, Germany) according to the International 10/20 system with Linked Ears montage (Fp1, Fp2, F7, F3, Fz, F4, F8, T3, C3, Cz, C4, T4, T5, $\mathrm{P} 3, \mathrm{Pz}, \mathrm{P} 4, \mathrm{~T} 6, \mathrm{O} 1$, and O2). For $3 \mathrm{~min}$, the EEG signals were obtained and collected simultaneously over those 19 channels with a Discovery20 amplifier (BrainMaster Technologies, Inc., Bedford, OH). The EEG recordings were recorded in an eyes-open condition, using BrainAvatar 4.6.4 (BrainMaster Technologies, Bedford, OH).

The EEG signals were imported into the Analyzer of BrainAvatar 4.6.4, a software for computation and analysis, where artefacts (i.e., activity collected from the EEG that was not produced by the brain) were visually inspected and removed. The EEG was processed with Linked Ears Montage, and Theta-toBeta ratio values were obtained for each participant. The Theta and Beta ranges were 4-8 $\mathrm{Hz}$ and 13-21 $\mathrm{Hz}$, respectively (Demos, 2019).

It was explained to each participant or to their parents how the different treatments (T/B and ZT) worked according to the scientific data available at that moment, and they chose which one to follow. The final layout for the treatments was that nine subjects followed the T/B and six followed the ZT.

\section{Neurofeedback}

\section{Theta/Beta Protocol Group}

This group received a $30-\mathrm{min}$ session twice a week in which the T/B protocol in $\mathrm{Cz}$ was applied with a total of 10 sessions. The sessions entailed inhibiting the Theta band, enhancing Beta, and inhibiting HiBeta. In our study, HiBeta range was $21-30 \mathrm{~Hz}$. Short videos selected by the subjects were used to produce the feedback. A dimmer was placed in front of the video screen which brightened up when the patient met the criteria of the protocol (Theta and HiBeta below the selected threshold, and Beta above the selected threshold) or became opaque, preventing the video from being viewed, when the criteria were not met.

\section{Z-scores Training Neurofeedback Group}

This group followed the Brain Avatar's ZT PZOKUL protocol (BrainMaster Technologies, Inc., Bedford, $\mathrm{OH}$ ) twice a week during a 30 -min session with a total of 10 sessions. The locations F3, F4, P3, and P4 were selected since this combination of locations in ZT protocols has been suggested to regulate whole head EEG activity (Collura, 2008). This protocol has a training threshold that auto-adjusts based on the percentage of $Z$-scores within the upper and lower selected limits. We used a one standard deviation as the upper and lower thresholds following the indications of some authors (Thatcher \& Lubar, 2015). Short videos selected by the subjects were used to produce the feedback. A dimmer was placed in front of the video screen which brightened up when the patient met the criteria or became opaque, preventing the video from being viewed, when the criteria were not met.

\section{Statistical Analysis}

The data were analyzed using version 25 SPSS software. Since our sample was small and heterogeneous, Mann-Whitney- $U$ and Wilcoxon signed-rank test analyses were utilized. Statistical significance was set at $\alpha=0.05$ for all analyses. Cohen's $d$ effect size was also calculated to assess the magnitude of the observed changes.

\section{Results}

Our sample was composed of 15 subjects with ADHD, 12 boys and 3 girls, which corresponds to the common 4:1 ratio in this disorder. There were six subjects in the ZT group and nine subjects in the T/B group. Theta-to-Beta ratios were calculated for each subject and group at $\mathrm{Cz}$ location. Those results can be found in Table 1. Both groups showed no significant differences regarding age $(U=19.50, p=$ 
.390), and there were no significant differences in the pretreatment Theta-to-Beta ratio between the groups $(U=24, p=.723)$.

\begin{tabular}{|c|c|c|c|c|}
\hline $\begin{array}{l}\text { Table } 1 \\
\text { Age and } \\
\text { at } C z\end{array}$ & treatm & nd po & atment & ratios \\
\hline & \multicolumn{2}{|c|}{ ZT Group } & \multicolumn{2}{|c|}{ T/B Group } \\
\hline & $M$ & $S D$ & $M$ & $S D$ \\
\hline Age & 11.17 & 3.97 & 12.56 & 3.28 \\
\hline $\begin{array}{c}\text { Pre } \\
\text { T/B ratio }\end{array}$ & 2.63 & 0.11 & 2.62 & 0.21 \\
\hline $\begin{array}{c}\text { Post } \\
\text { T/B ratio }\end{array}$ & 1.61 & 0.32 & 2.47 & 0.17 \\
\hline
\end{tabular}

After 10 treatment sessions, both groups presented a decrease of Theta-to-Beta ratio (Figure 1). The ZT group showed an average difference of 1.02 points, which was statistically significant $(W=-2.20, p=.02)$ and the $T / B$ group showed an average difference of 0.15 points, which was not significant $(W=-1.48, p=$ .110). Theta-to-Beta ratio's difference between both groups following the intervention was statistically significant $(U=5, p=.009)$. The Cohen's $d$ analysis found a large effect of group type $(d=1.39)$.

\section{Pre/Posttreatment Theta-to-Beta Ratio Difference}

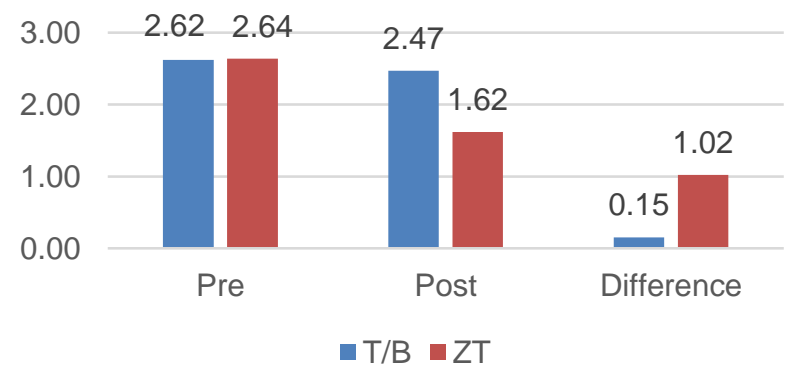

Figure 1. Theta-to-Beta Ratio, at $\mathrm{Cz}$, for each group preneurofeedback (pre), postneurofeedback (post) and difference pre-post (difference). The Theta and Beta ranges were $4-8 \mathrm{~Hz}$ and $13-21 \mathrm{~Hz}$, respectively.

\section{Discussion}

This retrospective study aimed to analyze the efficacy of a ZT intervention to regulate Theta-to-Beta ratio in a combined type ADHD sample. According to our findings, ZT is probably an effective way to regulate Theta-to-Beta ratio. Only 10 sessions created a large and statistically significant change in the desired direction. In addition, it had a bigger impact than the active control condition (T/B protocol) which did not produce a significant change after 10 sessions.

Even though the $T / B$ has shown its efficacy in reducing Theta-to-Beta ratio (Janssen et al., 2017) and in our study it also created changes in the desired direction, they were not significant. One reason could be the fact that it usually takes the power classical protocols up to 40 sessions or more to produce a significant effect (Bell, Moss, \& Kallmeyer, 2019; Krigbaum \& Wigton, 2014; Sürmeli \& Ertem, 2011; Sürmeli et al., 2012; Thatcher, 2013; Wigton, 2013; Wigton \& Krigbaum, 2015).

On the other hand, our results are consistent with previous studies about $\mathrm{ZT}$, in which there were relevant results in a few sessions (Bell et al., 2019; Pérez-Elvira et al., 2019; Wigton \& Krigbaum, 2015). Wigton and Krigbaum (2015), and Krigbaum and Wigton (2015), developed a method to monitor the progression of the $\mathrm{ZT}$ treatment and observed a normalization of the patients' EEG in approximately 10 intervention sessions. In the same vein, Groeneveld et al. (2019), following Krigbaum and Wigton's monitoring method (2015), found a normalization of the EEG in an average $30 \mathrm{ZT}$ sessions. Pérez-Elvira et al. (2019) reached the normalization of the EEG of a patient with insomnia in $30 \mathrm{ZT}$ sessions.

A possible reason for the $Z T^{\prime}$ 's superiority over the T/B protocol, at least regarding the number of sessions that are needed on each one, could be that amplitude NF allows to control a small number of factors at the same time (Soutar \& Longo, 2011). However, ZT could simultaneously train up to $248 Z$-scores (with 4 EEG channels) at the same time (Collura et al., 2010; Gracefire, 2016).

Even though there are enough studies that compare the use of NF, mostly its classical protocols, with other treatments, such as cognitive behavioral therapy (Moreno-García, Delgado-Pardo, Camacho-Vara de Rey, Meneres-Sancho, \& Servera-Barceló, 2015; Moreno-García, Meneres-Sancho, Camacho-Vara de Rey, \& Servera, 2019; Schönenberg et al., 2017), pharmacological (Bioulac et al., 2019; GonzálezCastro, Cueli, Rodríguez, García, \& Álvarez, 2016; Meisel, Servera, Garcia-Banda, Cardo, \& Moreno, 2014; Moreno-García et al., 2015, 2019; Razoki, 2018; Rossiter \& La Vaque, 1995; Yan, Zhang, Yuan, \& Cortese, 2018), there was only one prior study 
(Hammer et al., 2011) that had compared the efficacy of ZT with the one of a classical protocol. Hammer et al. (2011) found in their study improvements in sleep quality after $10 \mathrm{ZT}$ sessions in people with insomnia. But, in contrast to Hammer et al. (2011) who used a classical sensorimotor modified protocol combined with ZT, we used as active control a group who followed the classical T/B protocol.

This study had several obvious limitations; the most important ones being the small size of the sample and the lack of follow-up. Another limitation was the fact that the study was aimed at both treatment methodologies ( $\mathrm{ZT}$ and $\mathrm{T} / \mathrm{B}$ ) without explicitly considering the clinical variables, aside from the ADHD diagnosis, and thus there were no psychometric measures included. However, the study has provided certain evidence about the efficacy and the speed in reducing high Theta-to-Beta ratio, thus offering a foundation to study the same effect in future and more controlled investigations.

Moreover, the study has included effect size metrics, making it a candidate to be included in future metaanalysis. In conclusion, ZT seems to be a good and quick approach to reduce Theta-to-Beta ratio in ADHD patients.

\section{Author Disclosure}

The authors declare that they have no grants, financial interests, or conflicts of interest to disclose. This work is part of a doctoral thesis by Rubén PérezElvira.

\section{References}

Arns, M., de Ridder, S., Strehl, U., Breteler, M., \& Coenen, A. (2009). Efficacy of neurofeedback treatment in ADHD: The effects on inattention, impulsivity and hyperactivity: A metaanalysis. Clinical EEG and Neuroscience, 40(3), 180-189. https://doi.org/10.1177/155005940904000311

Bakhshayesh, A. R., Hänsch, S., Wyschkon, A., Rezai, M. J., \& Esser, G. (2011). Neurofeedback in ADHD: A single-blind randomized controlled trial. European Child \& Adolescent Psychiatry, 20(9), 481-491. https://doi.org/10.1007/s00787011-0208-y

Bell, A. N., Moss, D., \& Kallmeyer, R. J. (2019). Healing the neurophysiological roots of trauma: A controlled study examining LORETA $z$-score neurofeedback and HRV biofeedback for chronic PTSD. NeuroRegulation, 6(2), 54-70. https://doi.org/10.15540/nr.6.2.54

Bioulac, S., Purper-Ouakil, D., Ros, T., Blasco-Fontecilla, H., Prats, M., Mayaud, L., \& Brandeis, D. (2019). Personalized at-home neurofeedback compared with long-acting methylphenidate in an european non-inferiority randomized trial in children with ADHD. BMC Psychiatry, 19(1), 237. https://doi.org/10.1186/s12888-019-2218-0

Bluschke, A., Broschwitz, F., Kohl, S., Roessner, V., \& Beste, C. (2016). The neuronal mechanisms underlying improvement of impulsivity in ADHD by theta/beta neurofeedback. Scientific Reports, 6(1), 31178. https://doi.org/10.1038/srep31178
Carrobles, J. A. (2016). Bio/neurofeedback. Clínica y Salud, 27(3), 125-131. https://doi.org/10.1016/j.clysa.2016.09.003

Collura, T. F. (2008, April). Whole-head normalization using live $z-$ scores for connectivity training, Part 1. NeuroConnections, 12, $15,18-19$

Collura, T. F. (2014). Technical foundations of neurofeedback. New York, NY: Routledge/Taylor \& Francis Group.

Collura, T. F., Guan, J., Tarrant, J., Bailey, J., \& Starr, F. (2010). EEG biofeedback case studies using live $z$-score training and a normative database. Journal of Neurotherapy, 14(1), 22-46. https://doi.org/10.1080/10874200903543963

Demos, J. N. (2005). Getting started with neurofeedback (1st ed.). New York, NY: W. W. Norton \& Company.

Demos, J. N. (2019). Getting started with EEG neurofeedback (2nd ed.). New York, NY: W. W. Norton \& Company.

Doppelmayr, M., \& Weber, E. (2011). Effects of SMR and Theta/Beta neurofeedback on reaction times, spatial abilities, and creativity. Journal of Neurotherapy, 15(2), 115-129. https://doi.org/10.1080/10874208.2011.570689

González-Castro, P., Cueli, M., Rodríguez, C., García, T., \& Álvarez, L. (2016). Efficacy of neurofeedback versus pharmacological support in subjects with ADHD. Applied Psychophysiology and Biofeedback, 41(1), 17-25. https://doi.org/10.1007/s10484-015-9299-4

Gracefire, P. (2016). Introduction to the concepts and clinical applications of multivariate live $z$-score training, PZOK and sLORETA feedback. In T. F. Collura \& J. A. Frederick (Eds.), Handbook of clinical QEEG and neuropathy (pp. 326-383). New York, NY: Routledge.

Groeneveld, K. M., Mennenga, A. M., Heidelberg, R. C., Martin, R. E., Tittle, R. K., Meeuwsen, K. D., ... White, E. K. (2019). Z score neurofeedback and heart rate variability training for adults and children with symptoms of AttentionDeficit/Hyperactivity Disorder: A retrospective study. Applied Psychophysiology and Biofeedback, 44, 291-308. https://doi.org/10.1007/s10484-019-09439-x

Guan, J. (2016). The efficacy of $z$-score neurofeedback training. In T. F. Collura \& J. A. Frederick (Eds.), Handbook of clinical QEEG and neuropathy (pp. 312-325). New York, NY: Routledge.

Hammer, B. U., Colbert, A. P., Brown, K. A., \& llioi, E. C. (2011). Neurofeedback for insomnia: A pilot study of $z$-score SMR and individualized protocols. Applied Psychophysiology and Biofeedback, 36(4), 251-264. https://doi.org/10.1007/s10484011-9165-y

Janssen, T. W. P., Bink, M., Weeda, W. D., Geladé, K., van Mourik, R., Maras, A., \& Oosterlaan, J. (2017). Learning curves of theta/beta neurofeedback in children with ADHD. European Child \& Adolescent Psychiatry, 26(5), 573-582. https://doi.org/10.1007/s00787-016-0920-8

Koberda, J. L., Moses, A., Koberda, L., \& Koberda, P. (2012). Cognitive enhancement using 19-electrode $Z$-score neurofeedback. Journal of Neurotherapy, 16(3), 224-230. https://doi.org/10.1080/10874208.2012.705769

Kouijzer, M. E. J., de Moor, J. M. H., Gerrits, B. J. L., Congedo, M., \& van Schie, H. T. (2009). Neurofeedback improves executive functioning in children with autism spectrum disorders. Research in Autism Spectrum Disorders, 3(1), 145-162. https://doi.org/10.1016/j.rasd.2008.05.001

Krigbaum, G., \& Wigton, N. L. (2014). When discussing neurofeedback, does modality matter? NeuroRegulation, 1(1), 48-60. https://doi.org/10.15540/nr.1.1.48

Krigbaum, G., \& Wigton, N. L. (2015). A methodology of analysis for monitoring treatment progression with 19-channel $z$-score neurofeedback (19ZNF) in a single-subject design. Applied Psychophysiology and Biofeedback, 40(3), 139-149. https://doi.org/10.1007/s10484-015-9274-0

Leins, U., Goth, G., Hinterberger, T., Klinger, C., Rumpf, N., \& Strehl, U. (2007). Neurofeedback for children with ADHD: A comparison of SCP and Theta/Beta protocols. Applied 
Psychophysiology and Biofeedback, 32(2), 73-88. https://doi.org/10.1007/s10484-007-9031-0

Liu, Y., Hou, X., Sourina, O., \& Bazanova, O. (2016). Individual Theta/Beta based algorithm for neurofeedback games to improve cognitive abilities. In M. L. Gavrilova, C. J. K. Tan, A. Iglesias, M. Shinya, A. Galvez, \& A. Sourin (Eds.), Transactions on Computational Science XXVI (Vol. 9550, pp. 57-73). Berlin/Heidelberg, Germany: Springer-Verlag. https://doi.org/10.1007/978-3-662-49247-5_4

Lubar, J. F. (2015). Optimal procedures in z-score neurofeedback: Strategies for maximizing learning for surface and LORETA neurofeedback. In R. W. Thacher \& J. F. Lubar (Eds.), Z score neurofeedback: Clinical applications (pp. 41-58). San Diego, CA: Academic Press. https://doi.org/10.1016/B978-0-12801291-8.00003-0

Meisel, V., Servera, M., Garcia-Banda, G., Cardo, E., \& Moreno, I. (2014). Reprint of "Neurofeedback and standard pharmacological intervention in ADHD: A randomized controlled trial with six-month follow-up." Biological Psychology, 95, 116-125. https://doi.org/10.1016 /j.biopsycho.2013.09.009

Monastra, V. J., Lubar, J. F., \& Linden, M. (2001). The development of a quantitative electroencephalographic scanning process for attention deficit-hyperactivity disorder: Reliability and validity studies. Neuropsychology, 15(1), 136-144. https://doi.org/10.1037/0894-4105.15.1.136

Monastra, V. J., Lubar, J. F., Linden, M., VanDeusen, P., Green, G., Wing, W., ... Fenger, T. N. (1999). Assessing attention deficit hyperactivity disorder via quantitative electroencephalography: An initial validation study. Neuropsychology, 13(3), 424-433. https://doi.org/10.1037 10894-4105.13.3.424

Monastra, V. J., Lynn, S., Linden, M., Lubar, J. F., Gruzelier, J., \& La Vaque, T. J. (2005). Electroencephalographic biofeedback in the treatment of attention-deficit/hyperactivity disorder. Applied Psychophysiology and Biofeedback, 30(2), 95-114. https://doi.org/10.1007/s10484-005-4305-x

Monastra, V. J., Monastra, D. M., \& George, S. (2002). The effects of stimulant therapy, EEG biofeedback, and parenting style on the primary symptoms of attention-deficit/hyperactivity disorder. Applied Psychophysiology and Biofeedback, 27(4), 231-249. https://doi.org/10.1023 /A:1021018700609

Moreno-García, I., Delgado-Pardo, G., Camacho-Vara de Rey, C., Meneres-Sancho, S., \& Servera-Barceló, M. (2015). Neurofeedback, pharmacological treatment and behavioral therapy in hyperactivity: Multilevel analysis of treatment effects on electroencephalography. International Journal of Clinical and Health Psychology, 15(3), 217-225. https://doi.org/10.1016/j.ijchp.2015.04.003

Moreno-García, I., Meneres-Sancho, S., Camacho-Vara de Rey, C., \& Servera, M. (2019). A randomized controlled trial to examine the posttreatment efficacy of neurofeedback, behavior therapy, and pharmacology on ADHD measures. Journal of Attention Disorders, 23(4), 374-383. https://doi.org/10.1177/1087054717693371

Pérez-Elvira, R., Carrobles, J. A., López Bote, D. J., \& OltraCucarella, J. (2019). Efficacy of live $z$-score neurofeedback training for chronic insomnia: A single-case study. NeuroRegulation, 6(2), 93-101. https://doi.org/10.15540 /nr.6.2.93

Pérez-Elvira, R., López Bote, D. J., Guarino, S., Agudo Juan, M., De León, R. J., Feiner, T., \& Perez, B. (2018). Neurometric results of a case series using live Z-scores neurofeedback. International Journal of Psychophysiology, 131(Suppl.), S139-S140. https://doi.org /10.1016/j.ijpsycho.2018.07.375

Razoki, B. (2018). Neurofeedback versus psychostimulants in the treatment of children and adolescents with attentiondeficit/hyperactivity disorder: A systematic review.
Neuropsychiatric Disease and Treatment, 14, 2905-2913. https://doi.org/10.2147/NDT.S178839

Rossiter, T. (2002). Neurofeedback for AD/HD: A ratio feedback case study and tutorial. Journal of Neurotherapy, 6(3), 9-35. https://doi.org/10.1300/J184v06n03 03

Rossiter, T., \& La Vaque, T. J. (1995). A comparison of EEG biofeedback and psychostimulants in treating attention deficit/hyperactivity disorders. Journal of Neurotherapy, 1(1), 48-59. https://doi.org/10.1300/J184v01n01_07

Schabus, M., Heib, D. P. J., Lechinger, J., Griessenberger, H., Klimesch, W., Pawlizki, A., ... Hoedlmoser, K. (2014). Enhancing sleep quality and memory in insomnia using instrumental sensorimotor rhythm conditioning. Biological Psychology, 95, 126-134. https://doi.org/10.1016 /j.biopsycho.2013.02.020

Schönenberg, M., Wiedemann, E., Schneidt, A., Scheeff, J., Logemann, A., Keune, P. M., \& Hautzinger, M. (2017). Neurofeedback, sham neurofeedback, and cognitivebehavioural group therapy in adults with attention-deficit hyperactivity disorder: A triple-blind, randomised, controlled trial. The Lancet Psychiatry, 4(9), 673-684. https://doi.org/10.1016/S2215-0366(17)30291-2

Smith, M. L. (2008, April). A father finds a solution: Z-score training. NeuroConnections, 22, 24-25.

Soutar, R. G., \& Longo, R. E. (2011). Doing neurofeedback: An introduction. San Rafael, CA: ISNR Research Foundation.

Sürmeli, T., \& Ertem, A. (2011). Obsessive compulsive disorder and the efficacy of qEEG-guided neurofeedback treatment: A case series. Clinical EEG and Neuroscience, 42(3), 195-201. https://doi.org/10.1177/155005941104200310

Sürmeli, T., Ertem, A., Eralp, E., \& Kos, I. H. (2012). Schizophrenia and the efficacy of qEEG-guided neurofeedback treatment: $A$ clinical case series. Clinical EEG and Neuroscience, 43(2), 133-144. https://doi.org/10.1177/1550059411429531

Thatcher, R. W. (2013). Latest developments in live $z$-score training: Symptom check list, phase reset, and LORETA $z$ score biofeedback. Journal of Neurotherapy, 17(1), 69-87. https://doi.org/10.1080/10874208.2013.759032

Thatcher, R. W., \& Lubar, J. F. (Eds.). (2015). Z score neurofeedback: Clinical applications. San Diego, CA: Academic Press.

Walker, J. (2016). QEEG-guided neurofeedback to normalize brain function in various disorders. In T. F. Collura \& J. A. Frederick (Eds.), Handbook of clinical QEEG and neuropathy (pp. 149157). New York, NY: Routledge, Taylor \& Francis Group.

Wigton, N. L. (2013). Clinical perspectives of 19-channel $z$-score neurofeedback: Benefits and limitations. Journal of Neurotherapy, 17(4), 259-264. https://doi.org/10.1080 /10874208.2013.847142

Wigton, N. L. (2014). Evaluating 19-channel z-score neurofeedback: Addressing efficacy in a clinical setting. Phoenix, AZ: Grand Canyon University.

Wigton, N. L., \& Krigbaum, G. (2015). Attention, executive function, behavior, and electrocortical function, significantly improved with 19-channel $z$-score neurofeedback in a clinical setting: A pilot study. Journal of Attention Disorders, 23(4), 398-408. https://doi.org/10.1177/1087054715577135

Yan, L., Zhang, J., Yuan, Y., \& Cortese, S. (2018). Effects of neurofeedback versus methylphenidate for the treatment of attention-deficit/hyperactivity disorder protocol for a systematic review and meta-analysis of head-to-head trials. Medicine, 97(39), $\quad$ e12623. https://doi.org/10.1097 /MD.0000000000012623

Received: April 26, 2020

Accepted: May 12, 2020

Published: June 27, 2020 